\title{
POLA PERGERAKAN WANITA PENJAJA SEKS (WPS) DI KOTA PADANG
}

\author{
Jilham $^{1}$, Paus Iskarni ${ }^{2}$, Endah Purwaningsih ${ }^{2}$. \\ Program Studi Geografi \\ Fakultas Ilmu Sosial, Universitas Negeri Padang \\ Email: jilhammk@gmail.com
}

\begin{abstract}
Abstrak
Penelitian bertujuan untuk: 1) Memetakan pola pergerakan Wanita Penjaja Seks (WPS) di Kota Padang. 2) Mengetahui faktor yang mempengaruhi seseorang menjadi Wanita Penjaja Seks (WPS) di Kota Padang. Penelitian kualitatif ini bersifat deskriptif dan cenderung menggunakan analisis kualitatif. Sampel terdiri dari tiga elemen, yaitu tempat (place), pelaku (actor), dan aktivitas (activity). Teknik pengambilan sampel ialah SnowBall sampling sebanyak dua puluh lima (25) Wanita Penjaja Seks. Teknik Analisis Data adalah Analisis Pola Pergerakan dan Analisis Tabulasi Silang (crosstabs). Hasil dari penelitian ini adalah: 1) Berdasarkan analisis pola pergerakan yang bersumber dari Alan Leu dan Bob McKercher (2006) pola pergerakan Wanita Penjaja Seks (WPS) di Kota Padang tergolong pola Multiple Pattern jenis Chaining Loop sebanyak 48\% dan Base Site sebanyak28\%. 2) Faktor yang mempengaruhi seseorang menjadi Wanita Penjaja Seks di Kota Padang lebih dominan oleh faktor ekonomi lemah yaitu sebanyak $60 \%$.
\end{abstract}

\section{Kata Kunci: Wanita Penjaja Seks, Pola Pergerakan}

\begin{abstract}
The study aims to: 1) Mapping the movement patterns of sex workers (FSW) in Padang. 2) Knowing the factors that affect a person become sex workers (FSW) in Padang.This qualitative research is descriptive and tend to use qualitative analysis. The sample consists of three elements, namely where (place), actors (actor), and activity (activity). The sampling technique is snowball sampling as many as twenty-five (25) sex workers. Data Analysis Techniques Analysis Pattern is Movement and Cross Tabulation Analysis (crosstabs).The results of this research are: 1) Based on the analysis of movement patterns sourced from Alan Leu and Bob McKercher (2006) movement patterns of sex workers (FSW) in Padang classified patterns Multiple Pattern types Chaining Loop as much as 48\% and Base Site as much as 28\% 2) Factors that affect a person become sex workers in the city of Padang is more dominant factors, namely the weak economy as much as $60 \%$.
\end{abstract}

Keywords: sex workers, Movement Patterns

\footnotetext{
${ }^{1}$ Mahasiswa Program Studi Geografi untuk Wisuda September 2017

${ }^{2}$ Dosen Jurusan Geografi Fakultas Ilmu Sosial Universitas Negeri Padang
} 


\section{PENDAHULUAN}

Dunia pelacuran merupakan suatu profesi yang sangat tua usianya, setua umur kehidupan manusia. Pelacuran merupakan tingkah laku lepas bebas tanpa kendali dan cabul, karena adanya pelampiasan nafsu seks terhadap lawan jenisnya tanpa mengenal batas-batas kesopanan (Kartono, 2005).

Kasus mengejutkan penari striptease alias penari telanjang di tempat hiburan malam di Kota Padang yang terjadi beberapa tahun lalu menghebohkan masyarakat Kota Padang yang dikenal sebagai kota religi. Sebelumnya juga tersebar video mesum pelajar SMA salah satu sekolah di Padang (Padang Ekspress, 28/9). Kedua kasus amoral tersebut merupakan puncak es dari kegiatan prostitusi terselubung di Padang. Terbongkarnya pergaulan bebas kawula muda dan praktik maksiat di tempat-tempat hiburan malam, mencerminkan norma-norma agama dan adat sudah terkikis di negeri yang terkenal dengan filosofi "Adat Basandi Syarak, Syarak Basandi Kitabullah" (ABS-SBK).

Pasca gempa tahun 2009 lalu, perkembangan pariwisata Kota Padang semakin menggeliat, seiring dengan itu dunia hiburan malam juga ikut berkembang dengan pesat di daerah-daerah keramaian Kota Padang. Berdasarkan data dari Dinas Pariwisata Kota Padang terdapat sebanyak 61 objek wisata meliputi objek wisata alam, objek wisata bahari, objek wisata sejarah dan objek wisata buatan. Hiburan malam merupakan salah satu objek wisata buatan tersebut, hiburan malam Kota Padang terdapat pada beberapa kawasan, antara lain: kawasan Jembatan Siti Nurbaya, Pantai Padang, Pondok dan Taman Melati.
Menurut catatan terakhir Pemerintah Kota Padang, sejak tahun 2005 hingga tahun 2010 jumlah Wanita Penjaja Seks (WPS) di Kota Padang mencapai 2000 jiwa, jumlah tersebut termasuk Wanita Penjaja Seks yang sudah direhabilitasi dan yang masih beredar (Dinas Sosial, 2010). Sedangkan berdasarkan data Satpol PP dari tahun 2012-2014 terdapat 135 jiwa Wanita Penjaja Seks yang terjaring razia.

Bertolak dari permasalahan tersebut, peneliti tertarik mengkajinya berdasarkan kaidah ilmu geografi, dimana Wanita Penjaja Seks (WPS) sebagai objek yang mengisi dan bergerak dalam ruang atau wilayah geografis tersebut diteliti dengan judul "Pola Pergerakan Wanita Penjaja Seks (WPS) di Kota Padang".

\section{METODE PENELITIAN}

\section{Jenis Penelitian}

Penelitian ini dapat digolongkan pada jenis penelitian kualitatif. Dalam penelitian kualitatif proses dan makna (perspektif subyek) lebih ditonjolkan, landasan teori juga dimanfaatkan sebagai pemandu agar fokus penelitian sesuai dengan fakta di lapangan, Selain itu landasan teori juga bermanfaat untuk memberikan gambaran umum tentang latar penelitian dan sebagai bahan pembahasan hasil penelitian.

\section{Wilayah Penelitian}

Wilayah penelitian ini di sekitar kawasan Taman Melati dan Kawasan Pondok dimana terdapat cafe-cafe yang biasa dijadikan tempat mangkal dan mencari tamu atau pelanggan oleh Wanita Penjaja Seks (WPS).

\section{Batasan Penelitian}

Penelitian difokuskan pada Wanita Penjaja Seks Panggilan (Call girl prostitution) dan Wanita Penjaja 
Seks Terselubung (clandestine prostitution) saja.

\section{Subjek Penelitian}

Adapun informan pada penelitian ini adalah Mucikari sebanyak lima (5) orang dan Satuan Polisi Pamong Praja (Satpol PP) Kota Padang. Subjek penelitianya adalah Wanita Penjaja Seks (WPS) sebanyak dua puluh lima (25) orang.

\section{Jenis dan Sumber Data Penelitian}

Pada jenis data primer pada penelitian ini sumber data akan diperoleh dengan melakukan pendekatan penelitian observasi atau Participant observer yaitu suatu bentuk observasi dimana pengamat (observer) secara teratur berpartisipasi dan terlibat dalam kegiatan yang diamati.

\section{Variabel Penelitian}

a. Daerah Asal Wanita Penjaja Seks (WPS)

b. Tingkat Pendidikan Wanita Penjaja Seks (WPS)

c. Tempat Tinggal Wanita Penjaja Seks (WPS)

d. Tempat Mangkal Wanita Penjaja Seks (WPS) di dalam Kota Padang

e. Tempat Eksekusi atau hotel yang menjadi tempat eksekusi Wanita Penjaja Seks (WPS) di Kota Padang

7. Teknik Pengumpulan Data

a. Observasi partisipasi terbatas (Observer participant)

Kegiatan observasi yang peneliti lakukan adalah dengan melihat dan mengamati kehidupan dan perilaku Wanita Penjaja Seks (WPS) dalam menjalankan aktivitasnya mulai dari dimana tempat mangkalnya, lalu hotel mana yang menjadi tempat eksekusi serta kebiasaan lainnya dalam kehidupan sehari-hari yang dapat mendukung hasil penelitian ini.

\section{b. Wawancara Mendalam (indepth interview)}

Dimana peneliti membicarakan apa saja yang dianggap menarik untuk diperbincangkan. Setelah keakraban dirasakan maka dilakukan wawancara mendalam.

\section{c. Studi Dokumentasi}

Data ini dapat diperoleh dari perpustakaan, Badan Pusat Statistik (BPS), Dinas Sosial, dan bahan lainnya seperti buku-buku, jurnal dan penelitian yang berhubungan dengan kajian Wanita Penjaja Seks (WPS).

\section{Teknik Analisis Data}

a. Analisis Pola Pergerakan

Tabel.4. Pola Pergerakan berdasarkan Alan Leu dan Bob Mckrecher (2006).

\begin{tabular}{|c|c|}
\hline $\begin{array}{c}\text { Pola } \\
\text { Pergerakan }\end{array}$ & Penjelasan \\
\hline Single $P c$ & $\begin{array}{l}\text { Pergerakan yang } \\
\text { menuju hanya satu } \\
\text { titik destinasi tanpa } \\
\text { mengunjungi titik } \\
\text { destinasi lain dan } \\
\text { kembali ke tempat } \\
\text { asal menggunakan } \\
\text { rute yang sama. }\end{array}$ \\
\hline Base Site & $\begin{array}{lr}\text { Pola pergerakan } \\
\text { yang menyerupai } \\
\text { sebaran sinar dengan } \\
\text { satu titik pusat. } \\
\text { Wisatawan memulai } \\
\text { perjalanan } & \text { dari } \\
\text { tempat asal dan } \\
\text { menuju ke tujuan } \\
\text { utama, } & \text { dan } \\
\text { dilanjutkan } & \\
\text { melakukan } & \\
\text { kunjungan } & \text { sekunder } \\
\text { dalam } & \text { wilayah } \\
\text { tertentu. } & \end{array}$ \\
\hline Stopover & $\begin{array}{lr}\text { Pergerakan yang } \\
\text { menuju satu titik } \\
\text { destinasi utama } \\
\text { dimana mengunjungi } \\
\text { titik destinasi lain } \\
\text { (sekunder) dalam } \\
\text { proses }\end{array}$ \\
\hline
\end{tabular}




\begin{tabular}{|l|l|}
\hline & pergerakannya. \\
\hline Chaining & $\begin{array}{l}\text { Pergerakan dengan } \\
\text { tipe memutar seperti } \\
\text { cincin yang } \\
\text { menghubungkan 2 } \\
\text { atau lebih titik } \\
\text { destinasi dan tidak } \\
\text { terjadi pengulangan } \\
\text { rute. }\end{array}$ \\
\hline Restination & $\begin{array}{l}\text { Perjalanan yang } \\
\text { dimulai dengan rute } \\
\text { mengelilingi } \\
\text { destinasi lainnya. } \\
\text { Setelah } \\
\text { menyelesaikan tur } \\
\text { secara berkeliling } \\
\text { (pola lingkaran), } \\
\text { mereka kembali ke } \\
\text { tempat asal melalui } \\
\text { rute yang paling } \\
\text { singkat antara tujuan } \\
\text { utama dan tempat } \\
\text { asal berangkat. Ini } \\
\text { merupakan } \\
\text { kombinasi dari pola } \\
\text { single point dan } \\
\text { chaining loop. }\end{array}$ \\
\hline $\begin{array}{l}\text { Merupakan } \\
\text { kombinasi dua atau } \\
\text { lebih pola-pola yang } \\
\text { telah disebutkan di } \\
\text { atas. }\end{array}$ \\
\hline
\end{tabular}

Sumber: Lau \& McKercher (2006) dalam Myrna Sukmaratri (2013)

b. Analisis Tabulasi Silang (crosstabs)

Metode analisis ini digunakan untuk menguji korelasi antara variabel dalam tabel kontigensi sehingga diketahui apakah proporsi dari dua (2) peubah terjadi karena kebutuhan atau karena adanya asosiasi.

\section{HASIL PENELITIAN DAN} PEMBAHASAN

\section{Wanita Penjaja Seks (WPS) Kota Padang}

Berdasarkan pelaku yang terlibat dalam aktifitas prostitusi ini dan fungsinya dapat dilihat pada tabel 7 berikut:

Tabel 7. Pelaku dan fungsinya

\begin{tabular}{|c|c|c|}
\hline No & Pelaku & Fungsi \\
\hline 1 & $\begin{array}{l}\text { Wanita } \\
\text { Penjaja } \\
\text { Seks } \\
\text { (WPS) }\end{array}$ & \begin{tabular}{|lr} 
Bisa & dikatakan \\
sebagai barang yang \\
jasanyarana & dapat \\
diperdagangkan & \\
dalam & aktifitas \\
prostitusi &
\end{tabular} \\
\hline 2 & $\begin{array}{l}\text { Germo/ } \\
\text { Mucikari }\end{array}$ & 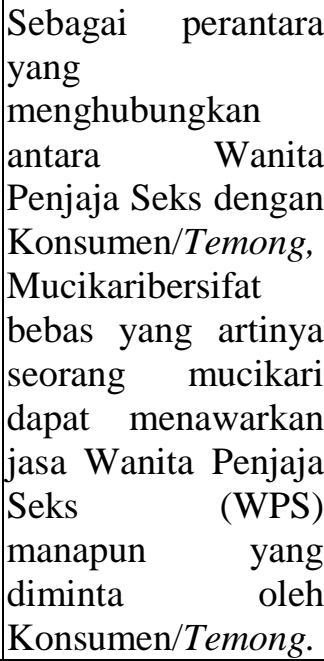 \\
\hline 3 & $\begin{array}{l}\text { Konsumen/ } \\
\text { Temong }\end{array}$ & $\begin{array}{lr}\text { Sebagai } & \text { predator } \\
\text { dalam } & \text { bisnis } \\
\text { prostitusi } & \text { yang } \\
\text { mampu } & \\
\text { menggunakan } & \text { jasa } \\
\text { Wanita } & \text { Penjaja Seks } \\
\text { (WPS) bisa berasal } \\
\text { dari dalam dan luar } \\
\text { kotar }\end{array}$ \\
\hline
\end{tabular}

\section{Wanita Penjaja Seks di Kota Padang Berdasarkan Daerah Asal}

Wanita Penjaja Seks (WPS) yang beraktivitas di Kota Padang tidak hanya berasal dari Kota Padang, melainkan terdapat Wanita Penjaja Seks yang berasal dari luar Kota Padang dan bahkan dari luar Provinsi Sumatera Barat. 
Tabel 8. Persentase Wanita Penjaja Seks Berdasarkan Daerah Asal di Kota

Padang

\begin{tabular}{|l|l|c|c|}
\hline No & Daerah Asal & $\begin{array}{l}\text { Jumlah } \\
(\text { Orang })\end{array}$ & $(\%)$ \\
\hline 1 & Payakumbuh & 4 & 16 \\
\hline 2 & $\begin{array}{l}\text { Solok } \\
\text { Selatan }\end{array}$ & 3 & 12 \\
\hline 3 & Solok & 3 & 12 \\
\hline 4 & Bukittinggi & 2 & 8 \\
\hline 5 & Medan & 3 & 12 \\
\hline 6 & $\begin{array}{l}\text { Pasaman } \\
\text { Timur }\end{array}$ & 1 & 4 \\
\hline 7 & $\begin{array}{l}\text { Dharmasray } \\
\text { a }\end{array}$ & 1 & 4 \\
\hline 8 & Jambi & 1 & 4 \\
\hline 9 & Pariaman & 1 & 4 \\
\hline 10 & Padang & 4 & 16 \\
\hline 11 & Batusangkar & 1 & 4 \\
\hline 12 & $\begin{array}{l}\text { Pesisir } \\
\text { Selatan }\end{array}$ & 1 & 4 \\
\hline Total & 25 & 100 & 100 \\
\hline Sumber: Hasil Pengolahan Data Primer
\end{tabular}

\section{Wanita Penjaja Seks di Kota Padang berdasarkan Tingkat Pendidikan}

Berdasarkan data Tingkat Pendidikan Wanita Penjaja Seks lebih doninan dari tamatan Sekolah Menengah Atas yaitu sebanyak 60\%, sisanya tamatan Sekolah Menengah Pertama 24\% dan Mahasiswi dan D3 masing $12 \%$ dan $4 \%$.

\section{Wanita Penjaja Seks di Kota Padang Berdasarkan Tempat Tinggal}

Tempat tinggal Wanita Penjaja Seks (WPS) yang tersebar di beberapa kecamatan Kota Padang, tempat tinggal Wanita Penjaja Seks (WPS) di Kota Padang juga bervariasi, ada yang tinggal di rumah sendiri, kos-kosan elit dan hotel.
Tabel 10. Persentase Wanita Penjaja Seks Berdasarkan Tempat Tinggal di Kota Padang

\begin{tabular}{|l|l|l|c|c|}
\hline No & $\begin{array}{r}\text { Tempat } \\
\text { Tinggal }\end{array}$ & Kecamatan & $\begin{array}{l}\text { Jumlah } \\
\text { (orang) }\end{array}$ & $(\%)$ \\
\hline 1 & Pondok & $\begin{array}{l}\text { Padang } \\
\text { Barat }\end{array}$ & 7 & 28 \\
\hline 2 & Veteran & $\begin{array}{l}\text { Padang } \\
\text { Barat }\end{array}$ & 4 & 16 \\
\hline 3 & Purus & $\begin{array}{l}\text { Padang } \\
\text { Barat }\end{array}$ & 4 & 16 \\
\hline 4 & $\begin{array}{l}\text { Bandar } \\
\text { Purus }\end{array}$ & $\begin{array}{l}\text { Padang } \\
\text { Barat }\end{array}$ & 2 & 8 \\
\hline 5 & $\begin{array}{l}\text { Lubuk } \\
\text { Buaya }\end{array}$ & $\begin{array}{l}\text { Koto } \\
\text { Tangah }\end{array}$ & 1 & 4 \\
\hline 6 & Tarandam & $\begin{array}{l}\text { Padang } \\
\text { Timur }\end{array}$ & 3 & 12 \\
\hline 7 & Lolong & $\begin{array}{l}\text { Padang } \\
\text { Utara }\end{array}$ & 1 & 4 \\
\hline 8 & Jati & $\begin{array}{l}\text { Padang } \\
\text { Timur }\end{array}$ & 1 & 4 \\
\hline 9 & $\begin{array}{l}\text { Ulak } \\
\text { Karang }\end{array}$ & $\begin{array}{l}\text { Padang } \\
\text { Utara }\end{array}$ & 2 & 8 \\
\hline \multicolumn{7}{|c|}{ Total } & 25 & 100 \\
\hline
\end{tabular}

Sumber: Hasil Pengolahan Data Primer 2015

\section{Wanita Penjaja Seks di Kota Padang Berdasarkan Tempat Mangkal}

Tempat mangkal yang menjadi favorit Wanita Penjaja Seks (WPS) Kota Padang adalah TB di Kecamatan Padang Barat yaitu sebanyak $72 \%$, sisanya di HFK dan NFC masinmasing $16 \%$ dan $12 \%$.

\section{Wanita Penjaja Seks di Kota Padang Berdasarkan Tempat Eksekusi / Tujuan}

Pemilihan tempat eksekusi di Kota Padang biasanya lebih diprioritaskan pada keinginan Wanita Penjaja Seks itu sendiri, hal tersebut menyangkut kenyamanan dan keamanan yang dirasakan oleh Wanita Penjaja Seks (WPS). 
Tabel 12. Berdasarkan Tempat

Eksekusi/ Tujuan di Kota Padang

\begin{tabular}{|l|l|l|l|l|}
\hline No & $\begin{array}{c}\text { Tempat } \\
\text { Eksekusi }\end{array}$ & Kecamatan & $\boldsymbol{f}$ & $\boldsymbol{( \% )}$ \\
\hline 1 & SH & $\begin{array}{l}\text { Padang } \\
\text { Barat }\end{array}$ & 4 & 5,80 \\
\hline 2 & HWH & $\begin{array}{l}\text { Padang } \\
\text { Barat }\end{array}$ & 5 & 7,25 \\
\hline 3 & PH & $\begin{array}{l}\text { Padang } \\
\text { Barat }\end{array}$ & 6 & 8,70 \\
\hline 4 & IMH & $\begin{array}{l}\text { Padang } \\
\text { Barat }\end{array}$ & 3 & 4,35 \\
\hline 5 & BMH & $\begin{array}{l}\text { Padang } \\
\text { Barat }\end{array}$ & 2 & 2,90 \\
\hline 6 & AxH & $\begin{array}{l}\text { Padang } \\
\text { Barat }\end{array}$ & 10 & 14,49 \\
\hline 7 & PCH & $\begin{array}{l}\text { Padang } \\
\text { Barat }\end{array}$ & 3 & 4,35 \\
\hline 8 & PBH & $\begin{array}{l}\text { Padang } \\
\text { Barat }\end{array}$ & 4 & 5,80 \\
\hline 9 & AlH & $\begin{array}{l}\text { Padang } \\
\text { Selatan }\end{array}$ & 8 & 11,59 \\
\hline 10 & MtH & $\begin{array}{l}\text { Padang } \\
\text { Barat }\end{array}$ & 5 & 7,25 \\
\hline 11 & GSH & $\begin{array}{l}\text { Padang } \\
\text { Selatan }\end{array}$ & 6 & 8,70 \\
\hline 12 & MeH & $\begin{array}{l}\text { Padang } \\
\text { Barat }\end{array}$ & 6 & 8,70 \\
\hline 13 & BH & $\begin{array}{l}\text { Padang } \\
\text { Utara } \\
\text { Barat }\end{array}$ & 1 & 1,45 \\
\hline 14 & OxH & 4 & 5,80 \\
\hline 15 & IH & 2 & 2,90 \\
\hline Total & 69 & 100 \\
\hline Parang & Padang \\
\hline
\end{tabular}

Sumber: Hasil Pengolahan Data Primer 2015

\section{Alat Transportasi Wanita Penjaja Seks Kota Padang}

Alat transportasi yang dominan digunakan oleh Wanita Penjaja Seks untuk mendukung aktivitas mereka adalah mobil rental khusus, mobil tersebut bukan alat angkutan yang sah tetapi mobil pribadi dengan pemiliknya sebagai sopir sewaan mengantar jemput Wanita Penjaja Seks dari Tempat Mangkal ke Tempat Eksekusi.

\section{Pola Pergerakan Wanita Penjaja Seks di dalam Kota Padang \\ Pola pergerakan yang terbentuk} terbanyak adalah Chaining Loop sebanyak 48\%, Base Site, 28\%, kemudian Destination Region Loop sebanyak $12 \%$, kemudian Complex Neighbourhood 12\%.

\section{Faktor Yang Mempengaruhi Pola Pergerakan}

a. Dalam Kota

1) Mencari tamu di tempat mangkal.

2) Menerima permintaan mucikari di lapangan untuk menemui tamu di tempat mangkal dan tempat eksekusi.

3) Memenuhi panggilan dari tamu untuk langsung menuju tempat eksekusi yang telah ditentukan.

b. Luar Kota

1) Menerima tawaran mucikari dari tempat yang dituju.

2) Mencari suasana baru dengan alasan supaya tamu tidak bosan.

3) Berpindah tempat domisili supaya tidak mudah di lacak oleh pihak yang berwajib.

\section{PENUTUP}

\section{Kesimpulan}

1. Berdasarkan analisis pola pergerakan Wanita Penjaja Seks (WPS) di Kota Padang tergolong pola multiple pattern jenis chaining loop sebanyak $48 \%$ dan base site sebanyak $28 \%$.

2. Faktor yang mempengaruhi seseorang menjadi Wanita Penjaja Seks di Kota Padang lebih dominan oleh faktor ekonomi lemah yaitu sebanyak $60 \%$.

\section{Saran}

1. Merelokasi Wanita Penjaja Seks (WPS) ke tempat khusus merupakan saran yang tepat jika di 
pandang dari segi keruangan, namun dalam masalah ini penulis berpendapat bahwa relokasi termasuk sebuah kebijakan yang mendukung prostitusi dan memfasilitasi untuk kehancuran moral generasi dimasa akan datang.

2. Wanita Penjaja Seks (WPS) diharapkan kesadarannya dengan sukarela ikut rehabilitasi yang disediakan oleh pemerintah agar dapat memiliki kemampuan di bidang lain yang lebih berguna dan bermanfaat untuk menuju masa depan yang lebih terarah.

3. Diharapkan kepada pemerintah Kota Padang untuk memperhatikan dan memberikan solusi yang tepat untuk mencegah prostitusi terselubung berkembang semakin marak dengan menindak tegas oknum-oknum yang terlibat dalam aktivitas prostitusi tersebut.
DAFTAR PUSTAKA

Alwi, Hasan, dkk. 2001. Kamus Besar

Bahasa Indonesia. Jakarta: Balai Bahasa

A.S, Alam. 1984. Pelacuran dan Pemerasan.Studi Sosiologis

Tentang Eksploitasi Manusia oleh Manusia. Bandung: Alumni

Bintarto dan Surastopo Hadisumarno. 1979. Metode analisis geografi. Jakarta: LP3S

Dulbahri. 1993. Sistem Informasi Geografi. Yogyakarta: PUSPICS-UGM

BAKOSURTANAL

Hasan, Moh. 1995. Mengenal Prilaku Abnormal. Yogyakarta: Kanisius

Kartono, Kartini.2005.Patologi Sosial Jilid II.Jakarta:PT Raja Grafindo Persada

Leu, Alan \& McKercher. 2006. Understanding Tourist Movement Pattern In a Destination: A GIS Approach.

Padang Ekspress. 2013. Edisi Senin 26 September

Tamin, O.Z. 2000. Perencanaan dan Pemodelan Transportasi Edisi Kedua. Bandung: ITB 